\title{
Effects of a thromboxane synthetase inhibitor (OKY-046) and a lipoxygenase inhibitor (AA-861) on bronchial responsiveness to acetylcholine in asthmatic subjects
}

\author{
MASAKI FUJIMURA, FUMIHIKO SASAKI, YASUTO NAKATSUMI, \\ YOSHIFUMI TAKAHASHI, SENSHU HIFUMI, KUNIAKI TAGA, \\ JUN-ICHIRO MIFUNE, TAKASHI TANAKA, TAMOTSU MATSUDA
}

From the Division of Pulmonary Disease, Fukui Cardiovascular Center, Fukui, and the Third Department of Internal Medicine, Kanazawa University School of Medicine, Kanazawa, Japan

ABSTRACT The effect of a selective thromboxane synthetase inhibitor, OKY-046, and a selective 5-lipoxygenase inhibitor, AA-861, on bronchial responsiveness to acetylcholine was studied in 23 asthmatic subjects. The provocative concentration of acetylcholine producing a $20 \%$ fall in forced expiratory volume in one second $\left(\mathrm{PC}_{20} \mathrm{FEV}_{1}\right)$ was measured before and after oral administration of OKY-046 (3000 mg over four days) and AA-861 (1100 mg over four days) and inhalation of OKY-046 (30 mg) in 10,10, and nine asthmatic subjects respectively. Baseline values of FEV 1 and forced vital capacity (FVC) were not altered by oral OKY-046, oral AA-861, or inhaled OKY-046. The geometric mean value of $\mathrm{PC}_{20} \mathrm{FEV}_{1}$ increased significantly from 0.55 to $2.24 \mathrm{mg} / \mathrm{ml}$ after oral OKY-046, but was unchanged after inhalation of OKY -046 and after oral administration of AA861 . These results suggest that thromboxane $A_{2}$ may play a part in bronchial hyperresponsiveness to acetylcholine.

One of the major clinical features of bronchial asthma is the increased bronchial responsiveness to various specific and non-specific stimuli. Thromboxane $A_{2}$, a metabolite of arachidonic acid, is a potent bronchoconstrictor. ${ }^{1}$ OKY-046 ((E)-3-[p-(1H-imidazole1-ylmethyl)phenyl]-2-propenoic acid hydrochloride monohydrate) is a selective thromboxane $A_{2}$ synthetase inhibitor. ${ }^{2}$ In guinea pigs it has been shown to suppress bronchoconstriction induced by allergen ${ }^{3}$ or by leukotrienes, prostaglandin $F_{2^{\alpha}}$, histamine, and acetylcholine. ${ }^{4}$ Indomethacin, a cyclooxygenase inhibitor, has been shown to reduce bronchial responsiveness to histamine in patients with asthma ${ }^{5}$ and the increase in bronchial responsiveness seen in dogs exposed to ozone. ${ }^{6}$ These findings implicate cyclo-oxygenase products such as thromboxane $A_{2}$ in bronchial hyperresponsiveness.

The lipoxygenase pathway is the other major route

Address for. reprint requests: Dr Masaki Fujimura, Third Department of Internal Medicine, Kanazawa School of Medicine, 13-1 Takara-machi, Kanazawa 920, Japan.

Accepted 30 June 1986 of arachidonic acid metabolism, producing the potent bronchoconstrictors leukotriene $\mathrm{C}_{4}, \mathrm{D}_{4}$, and $\mathrm{E}_{4},{ }^{78}$ the main components of slow reacting substance of anaphylaxis (SRS-A). ${ }^{9}$ These 5-lipoxygenase products are important chemical mediators in immediate type hypersensitivity reactions, ${ }^{70}$ but it is not clear whether they play a part in bronchial hyperresponsiveness. AA-861 (2,3,5-trimethyl-6-(12hydroxy-5,10-dodecadiynyl)-1,4-benzoquinone) is a selective 5-lipoxygenase inhibitor. ${ }^{11}$ In the present study we gave OKY-046 and AA-861 to investigate the role of thromboxane $A_{2}$ and 5-lipoxygenase products in the bronchial hyperresponsiveness of patients with asthma.

\section{Subjects and methods}

The subjects were 15 men and eight women with asthma attending the hospital, with a mean age of 57 (range 37-75) years. All showed an improvement of $15 \%$ or more in forced expiratory volume in one second $\left(\mathrm{FEV}_{1}\right)$ after inhalation of $300 \mu \mathrm{g}$ salbutamol sulphate. They all had intrinsic asthma with no familial 
history of allergic diseases and no increased levels of specific IgE antibodies. The test was performed when their symptoms were mild and stable while they were having oral bronchodilators (theophylline retard and $\beta_{2}$ stimulants) and mucolytic agents but not steroids. All medication was stopped at $9.00 \mathrm{pm}$ the previous day to allow a washout time of 18 hours before the measurement of bronchial responsiveness at $3.30 \mathrm{pm}$ on the test day.

Bronchial responsiveness was evaluated with acetylcholine. Acetylcholine chloride was dissolved in physiological saline to make solutions of $0.08,0 \cdot 16$, $0.31,0.63,1.25,2.5,5,10$, and $20 \mathrm{mg} / \mathrm{ml}$. Saline and acetylcholine were inhaled from a DeVilbiss 646 nebuliser (DeVilbiss Co, Somerset, Pennsylvania) operated by compressed air at $51 \mathrm{~min}^{-1}$. Saline was inhaled first for two minutes and $\mathrm{FEV}_{1}$ was measured (Autospiror HI-409, Chest Co Ltd, Japan). If the change in $\mathrm{FEV}_{1}$ from the baseline after inhalation of saline was $10 \%$ or less, inhalation of acetylcholine was started. When inhaled saline caused a larger change in $\mathrm{FEV}_{1}$ the test was stopped or postponed. Acetylcholine was inhaled for two minutes by tidal breathing with a nose clip, and this was followed immediately by spirometry. It was given in increasing concentrations until a fall of $20 \%$ or more in FEV was noted. The measured values were plotted on semilogarithmic graph paper and the acetylcholine concentration $\left(\mathrm{PC}_{20} \mathrm{FEV}_{1}\right)$ producing a $20 \%$ fall in $\mathrm{FEV}_{1}$ was calculated.

OKY-046 (Kissei Pharmaceutical Co Ltd, Matsumoto, and Ono Pharmaceutical Co Ltd, Osaka, Japan) was given orally in a dose of $200 \mathrm{mg} 4$ times a day for three days plus $200 \mathrm{mg}$ in the morning, at noon and at $3.00 \mathrm{pm}$ on the 4th day (test day). Bronchial responsiveness was then measured at $3.30 \mathrm{pm}$.

On a separate occasion OKY-046 solution $(30 \mathrm{mg} / \mathrm{ml})$ was inhaled with a DeVilbiss 646 nebuliser for two minutes, 10 minutes before the measurement of bronchial responsiveness to acetylcholine. About $30 \mathrm{mg}$ OKY-046 was inhaled.

AA-861 (Central Research Division, Takeda Chemical Industries Ltd, Osaka, Japan) was given at a dose of $100 \mathrm{mg}$ three times a day orally plus $100 \mathrm{mg}$ in the morning and at $1.30 \mathrm{pm}$ on the 4th day (test day). An acetylcholine challenge test was carried out at $3.30 \mathrm{pm}$.

Informed consent was obtained from all patients after the purpose of the test had been explained. No information on the test drugs and their pharmacological actions was given to the patients or the technical staff who performed the acetylcholine inhalation test.

DATA ANALYSIS

Acetylcholine $\mathrm{PC}_{20} \mathrm{FEV}_{1}$ values are expressed as

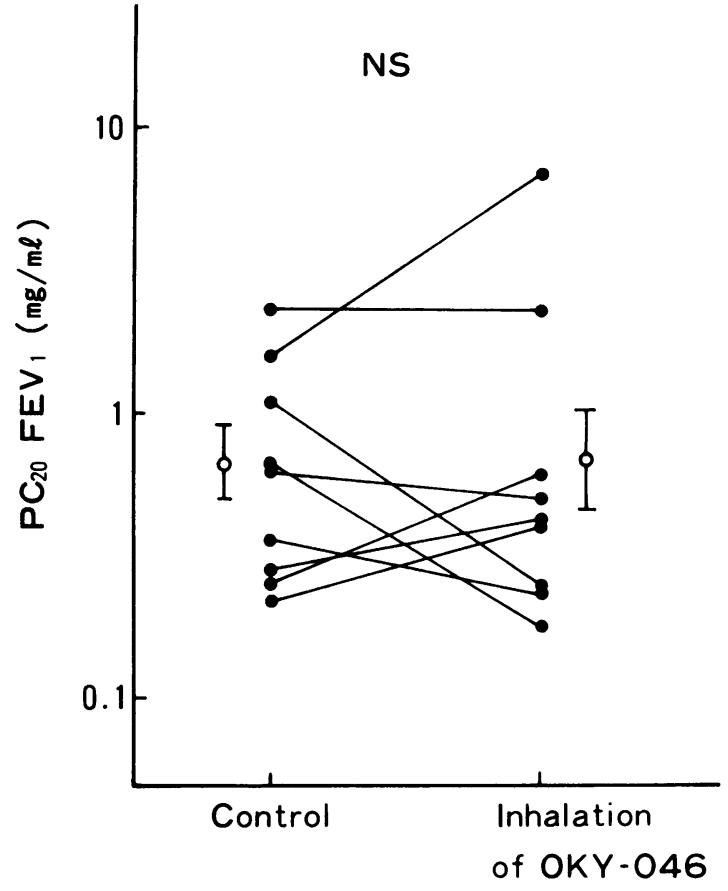

Fig 1 Effect of inhaled $O K Y-046$ on acetylcholine $P C_{20}$ $F E V_{1}$ (the provocative concentration of acetylcholine reducing $F E V_{1}$ by $20 \%$ ) in nine asthmatic subjects.

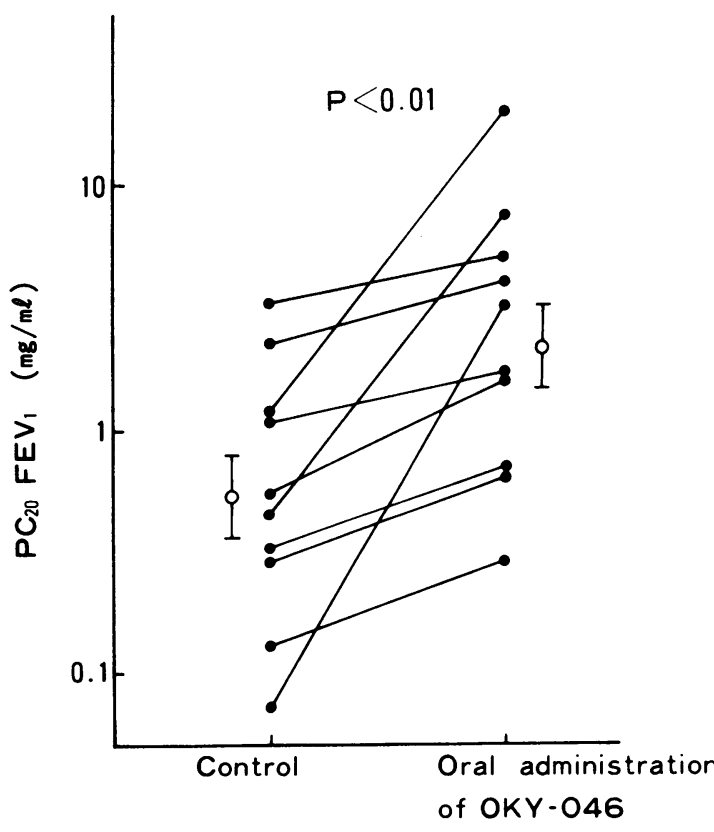

Fig 2 Effects of oral administration of $O K Y-046$ on acetylcholine $P C_{20} F E V_{1}$ (see fig 1 legend) in 10 asthmatic subjects. 
Details of the patients and their baseline forced vital capacity (FVC) and FEV (means with standard errors in parentheses)

\begin{tabular}{|c|c|c|c|c|c|c|}
\hline & \multicolumn{2}{|c|}{$\begin{array}{l}\text { Inhaled } O K Y-046 \\
(n=9)\end{array}$} & \multicolumn{2}{|c|}{$\begin{array}{l}\text { Oral OKY-046 } \\
(n=10)\end{array}$} & \multicolumn{2}{|c|}{$\begin{array}{l}\text { Oral AA-86I } \\
(n=10)\end{array}$} \\
\hline & Control & Pretreatment & Control & Pretreatment & Control & Pretreatment \\
\hline 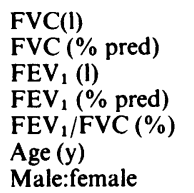 & $\begin{array}{l}2 \cdot 99(0 \cdot 2) \\
95(4) \\
1 \cdot 54(0 \cdot 2) \\
63(5) \\
53(6)\end{array}$ & $\begin{array}{l}3 \cdot 12(0 \cdot 3) \\
99(6) \\
1 \cdot 66(0 \cdot 2) \\
67(4) \\
55(5) \\
3\end{array}$ & $\begin{array}{l}2 \cdot 51(0 \cdot 2) \\
83(4) \\
1 \cdot 50(0 \cdot 2) \\
62(7) \\
57(5)\end{array}$ & $\begin{array}{l}2 \cdot 49(0 \cdot 2) \\
83(5) \\
1 \cdot 45(0 \cdot 2) \\
62(8) \\
56(6) \\
4\end{array}$ & $\begin{array}{l}2 \cdot 65(0 \cdot 3) \\
86(6) \\
1 \cdot 59(0 \cdot 2) \\
65(6) \\
59(3)\end{array}$ & $\begin{array}{l}2 \cdot 62(0 \cdot 3) \\
85(9) \\
1 \cdot 56(0 \cdot 2) \\
64(8) \\
59(4) \\
4\end{array}$ \\
\hline
\end{tabular}

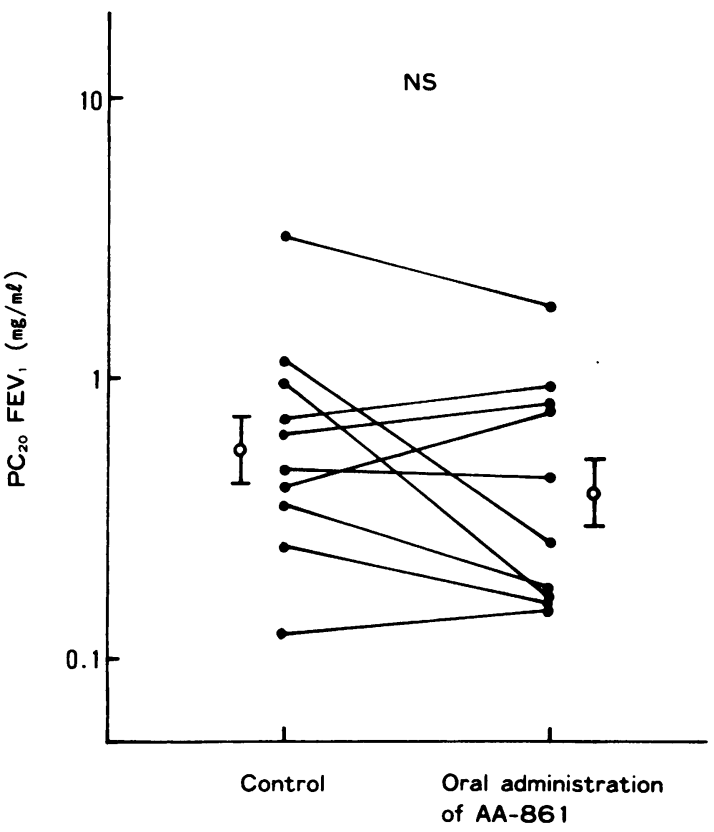

Fig 3 Effects of oral administration of $A A-861$ on acetylcholine $P C_{20} F_{1}$ (see fig 1 legend) in 10 asthmatic subjects.

geometric means with the geometric standard error of the mean (GSEM) expressed as a factor. Values for baseline FVC and $\mathrm{FEV}_{1}$ are reported as arithmetic means and standard errors of the mean (SEM).

Geometric mean $\mathrm{PC}_{20} \mathrm{FEV}_{1}$ values were compared by the paired $t$ test. A p value of 0.05 was taken as significant.

\section{Results}

Mean baseline values of FVC and $F_{1} V_{1}$ are shown before and after the administration of OKY-046 and AA-861 in the table. There was no significant difference in the $\mathrm{FEV}_{1}$ or FVC baseline values before and after each drug.
$\mathrm{PC}_{20} \mathrm{FEV}_{1}$ values before and after inhalation of OKY-046 are shown in figure 1 . The geometric mean values, $0.60($ GSEM 1.32$) \mathrm{mg} / \mathrm{ml}$ before and 0.59 (GSEM 1.48) $\mathrm{mg} / \mathrm{ml}$ after inhalation, did not differ significantly.

$\mathrm{PC}_{20} \mathrm{FEV}_{1}$ values before and after oral dosing with OKY-046 are shown in figure 2. There was a significant increase in $\mathrm{PC}_{20} \mathrm{FEV}_{1}(\mathrm{p}<0.01)$ after oral OKY -046 from 0.55 (GSEM 1.48 ) $\mathrm{mg} / \mathrm{ml}$ to 2.24 (GSEM 1.51$) \mathrm{mg} / \mathrm{ml}$.

$\mathrm{PC}_{20} \mathrm{FEV}_{1}$ values before and after oral dosing with AA-861 are shown in figure 3. There was no significant difference- $0.56 \quad$ (GSEM $\quad 1.32) \mathrm{mg} / \mathrm{ml}$ before and 0.39 (GSEM 1.32$) \mathrm{mg} / \mathrm{ml}$ after treatment.

There were no adverse effects from either oral OKY -046 or oral AA-861.

\section{Discussion}

Thromboxane synthetase inhibitors have been found to suppress bronchoconstriction caused by various bronchoconstrictive agents (histamine, serotonin, acetylcholine, bradykinin, and prostaglandin $F_{2 \alpha}$ ) in guinea pig tracheal strips. ${ }^{12}$ The thromboxane synthetase inhibitor OKY-046 has been shown to suppress airway anaphylaxis induced by antigen inhalation $^{3}$ and non-specific bronchoconstriction caused by various bronchoconstrictive agents. ${ }^{4}$ These findings suggest that thromboxane $A_{2}$ plays a part in the development of bronchial hyperresponsiveness in guinea pigs. In man, however, thromboxane $\mathbf{A}_{2}$ has not as yet been shown to be concerned in bronchial hyperresponsiveness, although thromboxane $A_{2}$ is released from lung parenchyma at the time of anaphylaxis. ${ }^{13}$

Walters et $a l^{5}$ reported that bronchial hyperresponsiveness to histamine in patients with asthma was suppressed by the cyclo-oxygenase inhibitor indomethacin. In dogs exposed to ozone the increase in bronchial responsiveness can be suppressed by indomethacin. ${ }^{6}$ These findings show a close connection between bronchial hyperresponsiveness and 
cyclo-oxygenase products, and would be consistent with the participation of thromboxane $A_{2}$, a potent bronchoconstrictor, in bronchial hyperresponsiveness. This study set out to determine whether thromboxane $A_{2}$ plays a part in bronchial hyperresponsiveness to acetylcholine in patients with asthma by using OKY $046,{ }^{1}$ a selective thromboxane synthetase inhibitor. The concentration of OKY -046 that gave a $50 \%$ inhibition $\left(\mathrm{IC}_{50}\right)$ of thromboxane synthetase in rabbit platelets was $1.1 \times 10^{-8} \mathrm{~mol} / \mathrm{l}$; the values for cyclooxygenase and prostaglandin $I_{2}$ synthetase were more than $1 \times 10^{-4} \mathrm{~mol} / \mathrm{l}^{2}$ and no inhibitory effect was seen at $1 \times 10^{-3} \mathrm{~mol} / \mathrm{l}$ on 5-lipoxygenase in cytosol of RBL-1 (personal communication). When given orally to healthy adults ${ }^{14}$ $25 \mathrm{mg}$ OKY -046 suppressed the ability of blood platelets to synthesise thromboxane $A_{2}$, while with higher doses $(200-400 \mathrm{mg})$ this suppression lasted for more than 12 hours and after the drug had disappeared from the blood. In the present study OKY-046 was given at a dose of $800 \mathrm{mg} /$ day for three days plus $600 \mathrm{mg}$ on the test day. This dose did not affect baseline pulmonary function, but bronchial hyperresponsiveness to acetylcholine was reduced. Suppression of thromboxane $A_{2}$ production is associated with increased production of prostaglandin $\mathrm{I}_{2}\left(\mathrm{PGI}_{2}\right){ }^{2}{ }^{15} \mathrm{PGI}_{2}$ has a potent blood vessel dilating effect, but no consistent bronchodilating effect in either normal subjects or asthmatic patients. ${ }^{16}$ It is likely therefore that the inhibitory effect of OKY-046 on bronchial hyperresponsiveness is due to a reduction in thromboxane $\mathbf{A}_{2}$ concentrations rather than increased $\mathrm{PGI}_{2}$ concentrations. In the present study OKY-046 given by inhalation caused no change in bronchial hyperresponsiveness. This may be a problem of bioavailability, possibly because the dose was too small or because it was inhaled only once, 10 minutes before the acetylcholine inhalation.

When Walters et $a l^{17}$ gave prostaglandin $\mathrm{E}_{2}$ $\left(\mathrm{PGE}_{2}\right)$ to normal subjects by inhalation bronchodilation occurred with a reduction in bronchial responsiveness. When bronchodilation ceased bronchial responsiveness was raised. Inhalation of prostaglandin $F_{2 \alpha}\left(P_{2 \alpha}\right)$ suppresses bronchial hyperresponsiveness in addition to causing bronchoconstriction. ${ }^{18}$ These findings with $\mathrm{PGE}_{2}$ and $\mathrm{PGF}_{2 \alpha}$ show some dissociation between their effect on bronchial calibre and their effect on bronchial responsiveness.

The 5-lipoxygenase pathway is the other major route of arachidonic acid metabolism. The metabolic products include SRS-A, which mainly consists of leukotriene $C_{4}, D_{4}$, and $E_{4},{ }^{70}$ all potent bronchoconstrictors. Leukotriene $\mathrm{D}_{4}$ increased bronchial responsiveness to histamine in guinea pigs, ${ }^{19}$ sug- gesting that leukotrienes might promote bronchial responsiveness at the time of allergic and inflammatory reactions. In the present study AA-861, a 5 -lipoxygenase inhibitor, caused no change in bronchial responsiveness in these asthmatic patients. AA861 has a dose dependent inhibitory effect on 5-lipoxygenase in guinea pig leucocytes $\left(\mathrm{IC}_{50}\right.$ of $3 \times$ $10^{-6} \mathrm{~mol} / \mathrm{l}$ ) but little effect on cyclo-oxygenase of bovine seminal vesicle gland (IC 50 of $1 \times 10^{-3} \mathrm{~mol} / 1$ or higher ${ }^{10}$ ). AA-861 also shows a dose dependent inhibitory effect on the release of $\mathrm{LTC}_{4}$ from human peripheral blood leucocytes induced by $\mathrm{Ca}^{++}$-ionophore A23187 $\left(\mathrm{IC}_{50} 1 \times 10^{-6} \mathrm{~mol} / \mathrm{l}\right.$ : unpublished data). Possibly when asthma symptoms are stable the spontaneous release of leukotrienes is not large of enough to affect bronchial responsiveness, and this $\frac{\text { ㅇ }}{2}$ may explain why in the present study the $\rightarrow$ 5-lipoxygenase inhibitor had no effect on bronchial responsiveness.

We wish to thank Kissei Pharmaceutical Company Ltd, Matsumoto; Ono Pharmaceutical Company Ltd, Osaka; and Takeda Chemical Industries Company Ltd, Osaka, Japan, for kindly supplying OKY-046 and AA-861, and also to express thanks to the participating technical staff, Mrs Fusako Yamada and Mrs Setsuko Matsugashita, for performing the measurements of bronchial hyperresponsiveness.

\section{References}

1 Svensson J, Strandberg K, Tuvemo T, Hamberg $M$. Thromboxane $\mathrm{A}_{2}$ : effects on airway and vascular smooth muscle. Prostaglandins 1977;14:425-36.

2 Naito J, Komatsu H, Ujiie A, Hamano S, Kubota T, $\underset{\times}{ }$ Tsuboshima M. Effects of thromboxane synthetase $\frac{\sigma}{3}$ inhibitors on aggregation of rabbit platelets. Eur $J$ Pharmacol 1983;91:41-8.

3 Fujimura M, Koshino K, Nishioka S, Matsuda T. Involvement of thromboxane $A_{2}$ in SRS-A-mediated 0 bronchoconstriction induced by aerosol antigen in the guinea pig. Kokyu 1984;3:1066-71.

4 Nishioka S, Kanamori K, Okafuji K, et al. Effects of OKY-046 on bronchoconstriction induced by inhalation of acetylcholine, histamine, prostaglandin $\mathrm{N}$ $\mathrm{F}_{2 \alpha}$ and leukotriene $\mathrm{C}_{4}$ in guinea pigs. Jap $\mathrm{J}$ Allergol $\mathrm{N}$ 1985;34:706-6.

5 Walters EH. Prostaglandins and the control of airways responses to histamine in normal and asthmatic subro jects. Thorax 1983;38:188-94.

6 O'Byrne PM, Walters EH, Aizawa $\mathrm{H}$, et al. Indomethacin inhibits the airway hyperresponsiveness but not the neutrophil influx induced by ozone in dogs. Am Rev Respir Dis 1984;130:220-24.

7 Murphy RC, Hammarström S, Samuelsson B. A slow reacting substance from murine mastocytoma cells. Proc Natl Acad Sci 1979;76:4275-9. 
8 Samuelsson B, Hammarström S. Nomenclature for leukotrienes. Prostaglandins 1980;19:645-8.

9 Kellaway $\mathrm{CH}$, Trethewie ER. The liberation of a slowreacting smooth muscle-stimulating substance in anaphylaxis. Quant J Exp Physiol 1940;30:121-45.

10 Brocklehurst WE. The release of histamine and formation of a slow reacting substance (SRS-A) during anaphylactic shock. J Physiol 1960;151:416-53.

11 Yoshimoto $\mathrm{T}$, Yokoyama $\mathrm{C}$, Ochi $\mathrm{K}$, et al. 2,3,5-Trimethyl-6-(12-hydroxy-5,10-dodecadinyl)-1,4benzoquinone (AA-861), a selective inhibitor of the 5-lipoxygenase reaction and the biosynthesis of slow reacting substance of anaphylaxis. Biochim Biophys Acta 1982;713:470-3.

12 Kitamura S, Ishihara Y, Takaku F. Effect of thromboxane synthetase inhibitors (OKY-046, OKY-1580) on the action of bronchoactive agents in guinea pig tracheal strips and on arachidonate metabolism in guinea pig lung lobes. Prostaglandins, Leukotrienes and Medicine 1984;14:341-50.

13 Shulman ES, Newball HH, Demers LM, Fitzpatrick FA, Adkinson NF. Anaphylactic release of thromboxane $A_{2}$, prostaglandin $D_{2}$ and prostacycline from human lung parenchyma. Am Rev Respir Dis 1981;124:402-6.
14 Ito T, Ogawa K. Sakai K. Effects of a selective inhibitor of thromboxane synthetase in humans. Advances in Prostaglandin, Thromboxane and Leukotriene Research 1983;11:245-50.

15 Uyama O, Nagatsuka K, Nakabayashi S, et al. The effect of a thromboxane synthetase inhibitor, OKY-046, on urinary excretion of immunoreactive thromboxane $\mathbf{B}_{2}$ and 6-keto-prostaglandin $F_{1 \alpha}$ in patients with ischemic cerebrovascular disease. Stroke 1985;16:241-4.

16 Hardy C, Robinson C, Lewis RA, Tattersfield AE, Holgate ST. Airway and cardiovascular responses to inhaled prostacyclin in normal and asthmatic subjects. Am Rev Respir Dis 1985;131:18-21.

17 Walters EH, Bevan C, Parrish RW, Davies BH, Smith AP. Time-dependent effect of prostaglandin $\mathbf{E}_{2}$ inhalation on airway responses to bronchoconstrictor agents in normal subjects. Thorax 1982;37:438-42.

18 Fish JE, Jameson LS, Albright A, Norman PS. Modulation of the bronchomotor effects of chemical mediators by prostaglandin $\mathrm{F}_{2 \alpha}$ in asthmatic subjects. Am Rev Respir Dis 1984;130:571-4.

19 Stewart AG, Thompson DC, Fennessy MR. Leukotriene $\mathrm{D}_{4}$ potentiates histamine-induced bronchoconstriction in guinea-pigs. Agents Actions 1984;15:146-52. 